\title{
BMJ Open Patient preference and choice of healthcare providers in Shanghai, China: a cross-sectional study
}

\author{
Wenya Yu, ${ }^{1}$ Meina Li, ${ }^{1}$ Feng Ye, ${ }^{2}$ Chen Xue, ${ }^{1}$ Lulu Zhang ${ }^{1}$
}

To cite: Yu W, Li M, Ye F, et al. Patient preference and choice of healthcare providers in Shanghai, China: a crosssectional study. BMJ Open 2017;7:e016418. doi:10.1136/ bmjopen-2017-016418

- Prepublication history for this paper is available online. To view these files, please visit the journal online (http://dx.doi. org/10.1136/bmjopen-2017016418).

WY, ML and FY contributed equally.

Received 14 February 2017 Revised 22 July 2017 Accepted 3 August 2017

\section{CrossMark}

${ }^{1}$ Department of Military Health Service Management, College of Military Health Service Management, Second Military Medical University, Shanghai, China

${ }^{2}$ Department of Medical Affairs, No. 187th hospital of PLA, Haikou, China

Correspondence to Professor Lulu Zhang; zllrmit@aliyun.com

\begin{abstract}
Objectives This study aimed to assess patients' healthcare-seeking preferences in mild, chronic, and serious illness; identify influential factors; and examine the reasons underlying patients' healthcare-seeking preference.

Design A retrospective study.

Setting The study was conducted in 14 tertiary hospitals in Shanghai, China.

Participants Questionnaires were distributed to 1519 patients, and 1114 were completed and returned. All patients participated in the study voluntarily, provided written informed consent, and possessed the ability to complete the questionnaire.
\end{abstract}

Main outcome measures We measured and compared preferences and choice of healthcare providers in patients if they had experienced mild, chronic, or serious illness. Results More than $50 \%$ of participants, including those who were $>60$ years of age, had consulted a doctor more than three times during the preceding year, were single, and were most likely to decide not to seek medical treatment. Community health facilities were the most frequently selected healthcare provider in mild illness. In addition, patients who had no personal preference, did not express a preference for a good environment or first-class medical technology, were concerned about close proximity and short waiting times, and pursued low medical costs were most likely to choose a community health facility. General hospitals were the most frequently selected healthcare provider in chronic and serious illness. In addition, patients who earned higher monthly incomes, did not pursue low medical costs, were not concerned about short waiting times or close proximity, and expressed a preference for first-class medical technology, were most likely to choose general hospitals.

Conclusion Patients' healthcare-seeking preference was influenced mainly by healthcare providers' characteristics, illness severity, and sociodemographic characteristics. These findings indicate that patients' current healthcareseeking preference was not ideal and requires optimisation.

\section{INTRODUCTION}

The Chinese healthcare system does not involve a strict general practitioner (GP) and referral system, and patient preference and choice of healthcare providers are influenced mainly by personal willingness to seek

\section{Strengths and limitations of this study}

The study included 1114 participants from 14 tertiary hospitals in Shanghai, one of the metropolises with the highest numbers of patients from different regions in China.

- Selection bias could have occurred in the study, as the participants were all from tertiary hospitals in Shanghai.

- Future research should include larger samples that are more representative of the wider Chinese population.

medical care. When individuals are ill, decisions as to whether to seek medical treatment and which healthcare provider to choose are made by patients and their family members. These choices are influenced mainly by personal preference, disease severity, and economic capacity. ${ }^{12}$ However, because they enjoy complete freedom, most people tend to choose doctors and hospitals (particularly top tertiary hospitals) with a good reputation regardless of disease type and severity; this was demonstrated in an investigation conducted in the Anhui province ${ }^{3}$ and a nationwide survey conducted in urban areas by the Chinese government. ${ }^{4}$ In addition, statistics showed that the number of visits to tertiary hospitals ( 1 billion) was 1.8 times that of visits to community health facilities (CHFs; 0.6 billion $),{ }^{5}$ which resulted in considerable wastage of high-quality medical resources (including abundant first-class doctors and modern, advanced equipment) in not only tertiary hospitals ${ }^{6}$ but also unused CHFs. This medical preference phenomenon in China has also caused additional problems, such as increased waiting times for patients ${ }^{7}$ and heavier workloads for doctors, in tertiary hospitals. For example, a survey conducted in two tertiary hospitals in the Shandong province in China showed that $60 \%$ of doctors felt that their workloads were too heavy, $70 \%$ experienced excessive work-related pressure, 
and only $3.3 \%$ were satisfied with their jobs. ${ }^{8}$ Therefore, there is an urgent need to optimise Chinese patients' current healthcare-seeking preferences, which could reduce both patients' waiting times and doctors' workloads in tertiary hospitals.

According to the domestic literature, healthcare-seeking preference involves two factors: whether to seek medical treatment and which healthcare provider to choose. Most studies focused on the latter, ${ }^{910}$ and only a small proportion considered the decision as to whether to seek medical care ${ }^{11} 12$ or treatment methods. ${ }^{13}$ These studies involved populations categorised according to the census register, ${ }^{29}$ occupation, ${ }^{14}{ }^{15}$ illness, ${ }^{16}{ }^{17}$ and age group. ${ }^{18}$ In addition, most studies involved quantitative research methods ${ }^{13}{ }^{19}$; however, qualitative research, ${ }^{20}$ mathematical functions, and models ${ }^{1}$ were also included. Furthermore, factors influencing patients' decision as to whether to seek healthcare included economic capacity, medical insurance, illness type and severity, medical technology, culture, and customs. ${ }^{11}{ }^{12}$ In addition, medical technology, the proximity of healthcare providers to patients' homes, economic factors, and illness severity were identified as the most significant factors affecting patients' choice of healthcare providers. ${ }^{9}{ }^{16}$ Participants' sociodemographic characteristics exerted a considerable influence on their decisions as well. ${ }^{3}$

We also analysed literature concerning other countries, in which the most popular topics included patients' preferences for treatment methods, ${ }^{21}$ factors influencing healthcare-seeking behaviour, ${ }^{22}$ factors associated with delays in seeking care, ${ }^{23}$ and policy research involving healthcare seeking. ${ }^{24}$ Most of the participants in this research were patients with particular medical conditions (eg, cancer, depression, and cardiovascular issues) ${ }^{23}{ }^{25}$ Unlike those identified in the findings of studies conducted in China, the most influential factors included social, cultural, and psychological variables (particularly fear and despair). ${ }^{26}$ Symptoms of illnesses, sociodemographic characteristics, and fear of medicine also played a role in patients' decision making. ${ }^{27} 28$

However, the studies described in the literature were subject to some limitations. The scope of the Chinese research was limited (eg, to a particular hospital) and was insufficient to provide theoretical evidence that could change patients' healthcare-seeking preferences in certain regions. Considering the well-established GP and referral systems in developed countries, their successful experiences cannot be applied in most lower and middle income countries. Therefore, the current study included patients from Shanghai, which is one of the areas in which high numbers of patients from different regions in China seek medical treatment. ${ }^{29}$ The aims of the study were to assess patients' healthcare-seeking preference in mild, chronic, and serious illness; identify influential factors; and examine the reasons underlying patients' healthcare-seeking preference.

\section{PATIENTS AND METHODS}

\section{Study design and instruments}

This study was a cross-sectional study. The required sample size was calculated as 1013, with a confidence level of $95 \%$, admissible error of 0.1 , a 2-week prevalence rate of $28.2 \%$, and 27006 outpatients hospitalised for 2 weeks in 14 tertiary hospitals. The questionnaire included 21 items divided between five dimensions. The dimensions pertained to participants' sociodemographic characteristics; decision not to seek medical treatment; and choice of healthcare providers in mild, chronic, and serious illness. Questionnaire items were extracted from $A n$ Analysis Report of National Health Services Survey in China, 2008 (NHSS), ${ }^{4}$ which was published by the National Health and Family Planning Commission of the People's Republic of China, and revised according to the findings of a preliminary investigation. Various basic characteristics, including sex, occupation, age, monthly income, marital status, and educational level, were assessed to examine participants' sociodemographic characteristics, which were completely consistent with the NHSS content. Participants' possession of medical insurance was used to determine the accessibility of healthcare services according to NHSS. In addition, self-assessment of health status and chronic disease, which were extracted from the NHSS and combined with the preliminary investigation findings, reflected healthcare demand. Hospitalisation during the preceding year, annual number of consultations with doctors, annual medical expenses, medical cost burden, and healthcare-seeking preference (ie, the most important influential factor) reflected healthcare utilisation. ${ }^{4}$ With respect to choosing not to seek medical treatment, we determined only whether participants had chosen not to seek medical treatment when they experienced illness. Choice of healthcare providers in mild, chronic, and serious illness included drug stores, clinics, specialised hospitals, CHFs, district hospitals, and general hospitals, based on the main types of healthcare institution in China. ${ }^{5}$ In addition, to determine which factors exerted the strongest effects on these choices, participants were required to choose from 10 factors: close proximity, short waiting times, low medical costs, a good environment, first-class medical technology, good service attitude, medical insurance, ${ }^{4}$ personal preference, acquaintance, and media publicity. ${ }^{30}$

Before the formal survey, 50 patients were recruited for participation in a preliminary investigation and excluded from the main analysis. The results of the preliminary survey showed that some items should be eliminated or revised because of non-response rate or poor feasibility, and the questionnaire demonstrated reliability and validity. Cronbach's $\alpha$ coefficient was calculated to determine the internal consistency of the questionnaire. The Kaiser-Meyer-Olkin (KMO) test and Bartlett's test of sphericity were used to screen for factorability. If Cronbach's $\alpha$ was $>0.70$ and the KMO result was $>0.70$, the questionnaire demonstrated good reliability and validity. 


\section{Data collection}

A survey of outpatients' healthcare-seeking preferences was conducted at 14 tertiary hospitals in Shanghai between June and September 2013. Of the 1519 questionnaires distributed, 1114 were completed and returned (valid response rate $=73.3 \%$ ). Patients were selected randomly using a random number table, which was based on outpatients' registration numbers. Patients participated in the survey voluntarily, and all participants provided written informed consent and were able to complete the questionnaire. The researchers explained the explicit meanings of some items to patients who experienced difficulty understanding the questionnaire.

\section{Statistical analysis}

All data were entered by two researchers simultaneously, using Epidata 3.1, and the data analysis was performed using SAS 8.0 and SPSS 18.0. Descriptive statistics were used to describe participants' basic characteristics. The relationships between healthcare-seeking preference and various factors were analysed via $\chi^{2}$ tests. Logistic regression analysis was performed to analyse the factors affecting the decision not to seek medical treatment and analyse factors affecting the choice of healthcare providers in patients with mild, chronic, and serious illness. The multinomial logistic regression analysis required a reference category for the dependent variable, against which the other categories of the dependent variable were compared to analyse the fit of the logistic regression models. The choice of general hospitals was defined as the reference category. All tests were two-way, and the significance level was set at $\mathrm{p}<0.05$.

\section{Ethics statement}

The study was approved by the ethics committee of the Second Military Medical University. All participants were aware of the aims and objectives of the study, informed that participation was voluntary and their data would remain confidential, and provided written informed consent.

\section{RESULTS}

\section{Test for the questionnaire}

Cronbach's $\alpha$ for the questionnaire was 0.723 , indicating that it demonstrated good reliability; in addition, the $\mathrm{KMO}$ value was 0.726 , and the $\mathrm{X}^{2}$ value in Bartlett's test of sphericity was $4490.20(\mathrm{p}<0.001)$, suggesting good validity.

\section{Participants' characteristics}

As shown in table 1 , of the 1114 participants, $52.8 \%$ were women and $47.2 \%$ were men. Participants aged between 20 and $39(44.7 \%)$ years and older than $60(21.3 \%)$ years accounted for the majority of the sample. With respect to occupation, the proportion of retirees $(25.7 \%)$ was the highest, followed by those of freelancers $(23.9 \%)$ and workers $(17.6 \%)$. In addition, $76.0 \%$ of participants

\section{Table 1 Basic characteristics of participants}

Category n (\%)

Sex

Male

$526(47.217)$

Female $588(52.783)$

Occupation

Freelancer 266 (23.878)

Soldier

$11(0.987)$

Medical staff $56(5.027)$

Civil servant

$50(4.488)$

Retiree $286(25.673)$

Farmer 131 (11.759)

Worker $196(17.594)$

Student

118 (10.592)

$\begin{array}{lc}\text { Age (years) } & 69(6.194) \\ <20 & 267(23.968) \\ 20-29 & 231(20.736) \\ 30-39 & 154(13.824) \\ 40-49 & 156(14.004) \\ 50-59 & 237(21.275) \\ \geq 60 & \end{array}$

Monthly incomes (CNY)

$\begin{array}{lc}<2000 & 393(35.278) \\ 2000-4999 & 538(48.294) \\ 5000-7999 & 122(10.952) \\ \geq 8000 & 61(5.476\end{array}$

Marital status

Divorced/widowed

36 (3.232)

Single

231 (20.736)

Married

847 (76.032)

Educational level

Primary school

82 (7.361)

Junior middle school

$270(24.237)$

Senior high school

296 (26.571)

College

$191(17.145)$

Undergraduate

218 (19.569)

Master's/doctorate

57 (5.117)

Medical insurance

\begin{tabular}{lc} 
No & $57(5.117)$ \\
Yes & $1057(94.883)$ \\
Self-assessment of health status & \\
Very poor & $32(2.873)$ \\
Poor & $116(10.413)$ \\
Moderate & $439(39.408)$ \\
Well & $426(38.241)$ \\
$\quad$ Very well & $101(9.066)$ \\
Chronic disease & \\
\hline
\end{tabular}

Continued 


\section{Table 1 Continued}

\begin{tabular}{cc}
\hline Category & n (\%) \\
\hline No & $468(42.011)$ \\
Yes & $646(57.989)$
\end{tabular}

Hospitalisation during the preceding year

No

$843(75.673)$

Yes

$271(24.327)$

Annual number of consultations with doctors

0

$1-3$

$\geq 3$

Annual medical expenses (CNY)

$<1000$

$1000-4999$

5000-9999

$\geq 10000$

Medical cost burden

Cannot undertake

Can mainly undertake

Can entirely undertake

Choice not to seek medical treatment in illness

$\begin{array}{ll}\text { No } & 411(36.894) \\ \text { Yes } & 703(63.106)\end{array}$

Choice of healthcare providers in mild illness

$\begin{array}{lc}\text { Drug stores } & 59(5.296) \\ \text { Clinics } & 44(3.950) \\ \text { Specialised hospitals } & 64(5.745) \\ \text { Community health facilities } & 365(32.765) \\ \text { District hospitals } & 257(23.070) \\ \text { General hospitals } & 325(29.174)\end{array}$

Choice of healthcare providers in chronic illness

\begin{tabular}{|lc}
\hline Drug stores & $13(1.167)$ \\
\hline Clinics & $12(1.077)$ \\
\hline Specialised hospitals & $167(14.991)$ \\
\hline Community health facilities & $148(13.285)$ \\
\hline District hospitals & $260(23.339)$ \\
\hline General hospitals & $514(46.140)$ \\
\hline Choice of healthcare providers in serious illness \\
\hline Drug stores & $4(0.359)$ \\
\hline Clinics & $2(0.180)$ \\
\hline Specialised hospitals & $194(17.415)$ \\
\hline Community health facilities & $35(3.142)$ \\
\hline District hospitals & $81(7.271)$ \\
\hline General hospitals & $798(71.634)$ \\
\hline
\end{tabular}

were married, $83.6 \%$ earned $<5000 \mathrm{CNY}$ per month, and more than half were educated to junior middle $(24.2 \%)$ or senior high (26.6\%) school level. Moreover, most participants' self-assessed their health status as moderate $(39.4 \%)$ or good $(38.2 \%)$, and $75.7 \%$ had not been hospitalised during the preceding year. However, $58.0 \%$ of participants had chronic illness and $49.6 \%$ had consulted a doctor between one and three times during the preceding year. Almost all $(94.9 \%)$ participants had some type of medical insurance, and $79.1 \%$ were mainly or entirely able to manage the burden of medical costs. Of these participants, $63.1 \%$ had chosen not to seek medical treatment at least once while they were ill. With respect to the selection of healthcare providers, $32.8 \%, 29.2 \%$, and $23.1 \%$ of participants had selected CHFs, general hospitals, and district hospitals, respectively, when they had experienced mild illness. In addition, $46.1 \%, 23.3 \%$, and $15.0 \%$ of participants had selected general, district, and specialised hospitals, respectively, when they had experienced chronic illness. Moreover, $71.6 \%$ and $17.4 \%$ of participants had selected general and specialised hospitals, respectively, when they had experienced serious illness (table 1).

\section{Preference and the decision not to seek medical treatment}

Univariate analysis of influential factors

Univariate analysis was performed to analyse preference and the decision not to seek medical treatment. Aside from the participants' basic characteristics, the following seven factors were included in the analysis as the most important factors influencing participants' choices: hospital reputation, medical technology, service attitude, medical costs, equipment, accessibility, and environment (table 2).

Of the factors included in the $\chi^{2}$ test, sex $(p=0.013)$, occupation $(p=0.011)$, age $(p=0.012)$, marital status $(\mathrm{p}=0.002)$, self-assessment of health status $(\mathrm{p}=0.008)$, annual number of consultations with doctors $(p<0.0001)$, and annual medical expenses $(p=0.033)$ were statistically significant factors affecting patients' decision not to seek medical treatment when they experienced illness (table 2).

Logistic regression analysis of the decision not to seek medical treatment in illness

Based on the results of the $\chi^{2}$ test, only the factors that significantly affected the decision not to seek medical treatment in the univariate analysis were included in the logistic regression analysis. The decision as to whether to seek medical treatment when experiencing illness was included as the dependent variable $(0=$ decision to seek medical treatment when experiencing illness (reference category); $1=$ decision not to seek medical treatment when experiencing illness). The results of the logistic regression analysis showed that only age, marital status, and annual number of consultations with doctors were statistically significant factors. Younger participants $(<20 \mathrm{vs} \geq 60$ years; OR 0.350) and participants who reported fewer consultations with doctors ( $\leq 3$ times vs $>3$ times; OR 0.499 ) were less likely to decide not to seek medical treatment. In addition, single participants were 1.940 times 
Table 2 Influential factors of preference and decision not to seek medical treatment in illness

95\% Wald Cl

\begin{tabular}{|c|c|c|c|c|c|c|c|}
\hline \multirow[b]{2}{*}{ Category } & \multirow[b]{2}{*}{$\chi^{2}$} & \multirow[b]{2}{*}{$\mathbf{p}$} & \multirow[b]{2}{*}{ Estimate } & \multirow[b]{2}{*}{ p Value } & \multirow[b]{2}{*}{ OR } & \multicolumn{2}{|l|}{ 95\% Wald Cl } \\
\hline & & & & & & Lower limit & Upper limit \\
\hline Sex & 6.149 & $0.013^{*}$ & & & & & \\
\hline Female & & & Ref & & & & \\
\hline Occupation & 18.195 & $0.011^{*}$ & & & & & \\
\hline Soldier & & & 1.111 & 0.326 & 3.036 & 0.331 & 27.890 \\
\hline Medical staff & & & -0.457 & 0.334 & 0.633 & 0.250 & 1.602 \\
\hline Civil servant & & & -0.275 & 0.589 & 0.760 & 0.281 & 2.058 \\
\hline Retiree & & & -0.897 & 0.059 & 0.408 & 0.161 & 1.034 \\
\hline Farmer & & & -0.199 & 0.662 & 0.820 & 0.336 & 2.002 \\
\hline$<20$ & & & -1.051 & 0.044 & 0.350 & 0.126 & 0.973 \\
\hline $20-29$ & & & -0.081 & 0.804 & 0.923 & 0.488 & 1.744 \\
\hline 30-39 & & & -0.294 & 0.320 & 0.745 & 0.417 & 1.331 \\
\hline $40-49$ & & & -0.001 & 0.996 & 0.999 & 0.555 & 1.796 \\
\hline $50-59$ & & & -0.241 & 0.299 & 0.786 & 0.499 & 1.239 \\
\hline$\geq 60$ & & & Ref & & & & \\
\hline Monthly incomes (CNY) & 7.050 & 0.070 & Not included & & & & \\
\hline \multicolumn{8}{|l|}{$<2000$} \\
\hline Married & & & Ref & & & & \\
\hline Educational level & 8.641 & 0.124 & Not included & & & & \\
\hline \multicolumn{8}{|l|}{ Primary school } \\
\hline \multicolumn{8}{|l|}{ Junior middle school } \\
\hline \multicolumn{8}{|l|}{ Senior high school } \\
\hline \multicolumn{8}{|l|}{ College } \\
\hline \multicolumn{8}{|l|}{ Undergraduate } \\
\hline \multicolumn{8}{|l|}{ Master's/doctorate } \\
\hline Medical insurance & 3.859 & 0.050 & Not included & & & & \\
\hline \multicolumn{8}{|l|}{ No } \\
\hline \multicolumn{8}{|l|}{ Yes } \\
\hline $\begin{array}{l}\text { Self-assessment of health } \\
\text { status }\end{array}$ & 13.729 & $0.008^{*}$ & & & & & \\
\hline Very poor & & & -0.472 & 0.318 & 0.624 & 0.247 & 1.575 \\
\hline Poor & & & 0.439 & 0.190 & 1.551 & 0.805 & 2.989 \\
\hline Moderate & & & 0.366 & 0.154 & 1.443 & 0.872 & 2.386 \\
\hline Well & & & 0.244 & 0.321 & 1.276 & 0.788 & 2.067 \\
\hline
\end{tabular}


Open Access

Table 2 Continued

\begin{tabular}{|c|c|c|c|c|c|c|c|}
\hline \multirow[b]{2}{*}{ Category } & \multirow[b]{2}{*}{$\chi^{2}$} & \multirow[b]{2}{*}{$\mathbf{p}$} & \multirow[b]{2}{*}{ Estimate } & \multirow[b]{2}{*}{ p Value } & \multirow[b]{2}{*}{ OR } & \multicolumn{2}{|l|}{ 95\% Wald Cl } \\
\hline & & & & & & Lower limit & Upper limit \\
\hline Very well & & & Ref & & & & \\
\hline \multicolumn{8}{|l|}{ No } \\
\hline \multicolumn{8}{|l|}{ Yes } \\
\hline \multicolumn{8}{|l|}{ No } \\
\hline \multicolumn{8}{|l|}{ Yes } \\
\hline $\begin{array}{l}\text { Annual number of } \\
\text { consultations with doctors }\end{array}$ & 21.620 & $0.000^{*}$ & & & & & \\
\hline $\begin{array}{l}\text { Annual medical expenses } \\
\text { (CNY) }\end{array}$ & 8.720 & $0.033^{*}$ & & & & & \\
\hline$<1000$ & & & 0.265 & 0.342 & 1.303 & 0.755 & 2.249 \\
\hline $1000-4999$ & & & 0.486 & 0.056 & 1.625 & 0.988 & 2.673 \\
\hline 5000-9999 & & & 0.312 & 0.298 & 1.366 & 0.759 & 2.461 \\
\hline$\geq 10000$ & & & Ref & & & & \\
\hline Medical cost burden & 1.851 & 0.396 & Not included & & & & \\
\hline \multicolumn{8}{|l|}{ Cannot undertake } \\
\hline \multicolumn{8}{|l|}{ Can mainly undertake } \\
\hline \multicolumn{8}{|l|}{ Yes } \\
\hline \multicolumn{8}{|l|}{ No } \\
\hline \multicolumn{8}{|l|}{ Yes } \\
\hline Service attitude & 0.258 & 0.611 & Not included & & & & \\
\hline \multicolumn{8}{|l|}{ No } \\
\hline \multicolumn{8}{|l|}{ Yes } \\
\hline Medical costs & 3.191 & 0.074 & Not included & & & & \\
\hline \multicolumn{8}{|l|}{ No } \\
\hline \multicolumn{8}{|l|}{ Yes } \\
\hline Equipment & 0.174 & 0.676 & Not included & & & & \\
\hline \multicolumn{8}{|l|}{ No } \\
\hline \multicolumn{8}{|l|}{ Yes } \\
\hline Accessibility & 0.000 & 0.985 & Not included & & & & \\
\hline No & & & & & & & \\
\hline Yes & & & & & & & \\
\hline Environment & 0.032 & 0.859 & Not included & & & & \\
\hline No & & & & & & & \\
\hline Yes & & & & & & & \\
\hline
\end{tabular}

${ }^{*}$ Indicates statistically significant results $(p<0.05)$. 
more likely not to consult a healthcare provider than they were to consult a healthcare provider when they were ill (OR 1.940; table 2).

\section{Preference and choice of healthcare providers in mild illness} Univariate analysis of influential factors

Univariate analysis was performed to examine preference and choice of healthcare providers in mild illness. Participants' basic characteristics and the following 10 additional factors were included in the univariate analysis: personal preference, close proximity, short waiting times, low medical costs, having an acquaintance in the health institution, a good environment, first-class medical technology, medical insurance, a good service attitude, and media publicity (table 3 ).

Of the participants' basic characteristics and the 10 factors included in the univariate analysis, sex $(p=0.006)$, occupation $(p<0.0001)$, age $(p<0.0001)$, monthly income $(\mathrm{p}<0.0001)$, educational level $(p<0.0001)$, medical cost burden $(p=0.007)$, personal preference $(p<0.0001)$, close proximity $(p<0.0001)$, short waiting times $(p<0.0001)$, low medical costs $(\mathrm{p}<0.0001)$, a good environment $(\mathrm{p}<0.0001)$, firstclass medical technology $(\mathrm{p}<0.0001)$, and media publicity $(\mathrm{p}=0.020)$ were statistically significant factors affecting patients' choice of healthcare providers in mild illness (table 3 ).

\section{Logistic regression analysis of the choice of healthcare providers} in mild illness

Only the factors that were significant in the univariate analysis were included in the logistic regression analysis. Healthcare provider was included as the dependent variable ( $1=$ drug stores, $2=$ clinics, $3=$ specialised hospitals, $4=\mathrm{CHFs}, 5=$ district hospitals, and $6=$ general hospitals (reference category)) in the logistic regression analysis. In addition, the multinomial logistic regression analysis required that the explanation of results should compare the choice of drug stores, clinics, specialised hospitals, CHFs, and district hospitals with the choice of general hospitals.

The results of the logistic regression analysis showed that patients who worked as farmers (OR 6.544), were freelancers (OR 10.492), were younger than 20 years of age (OR 11.303), reported higher educational levels (ie, master's degree or doctorate), pursued low medical costs, and did not express a preference for first-class medical technology (OR 12.258) were more likely to choose a drug store. Patients who were younger than 20 years of age (OR 23.054) or aged between 30 and 39 years (OR 8.742 ), valued short waiting times, pursued low medical costs, and did not express a preference for first-class medical technology (OR 5.390) were more likely to choose a clinic. Patients who worked as soldiers (OR 45.666) or civil servants (OR 19.705), had no personal preference (OR 2.648), and were not concerned about close proximity (OR 2.827) were more likely to choose a specialised hospital. Men (OR 1.902) and patients who had no personal preference (OR 2.200), did not express a preference for a good environment (OR 2.068) or first-class medical technology (OR 8.311), were concerned about close proximity and short waiting times, and pursued low medical costs were more likely to choose a CHF. Patients who reported lower educational levels (ie, junior middle school, senior high school, or college), had no personal preference (OR 1.973), did not express a preference for first-class medical technology (OR 2.557), and were concerned about close proximity and short waiting times were more likely to choose a district hospital (table 4).

\section{Preference and choice of healthcare providers in chronic illness \\ Univariate analysis of influential factors}

Factors included in the univariate analyses of factors for chronic illness were similar to those included for mild illness. The results of the univariate analysis showed that sex $(\mathrm{p}=0.033)$, occupation $(\mathrm{p}=0.003)$, age $(\mathrm{p}=0.002)$, monthly income $(\mathrm{p}<0.0001)$, educational level $(\mathrm{p}<0.0001)$, self-assessment of health status $(\mathrm{p}=0.043)$, annual number of consultations with doctors $(\mathrm{p}=0.005)$, annual medical expenses $(\mathrm{p}=0.026)$, medical cost burden $(\mathrm{p}=0.001)$, personal preference $(\mathrm{p}=0.001)$, close proximity $(\mathrm{p}<0.0001)$, short waiting times $(\mathrm{p}<0.0001)$, low medical costs $(p<0.0001)$, a good environment $(p<0.0001)$, and a preference for first-class medical technology $(p<0.0001)$ were statistically significant factors affecting the choice of healthcare providers in chronic illness (table 3).

\section{Logistic regression analysis of choice of healthcare providers in chronic illness}

The assignment of the dependent variable was similar to that in the logistic regression analysis of choice of healthcare providers in mild illness. The results showed that men (OR 12.585) and patients who did not express a preference for first-class medical technology (OR 7.135) were more likely to choose a drug store. In contrast, patients who reported monthly incomes of between 1000 and 4999 CNY (OR 0.039) and were not concerned about short waiting times (OR 0.071) or medical costs (OR 0.016), were less likely to choose a drug store. Patients who pursued low medical costs (OR 0.008) were more likely to choose a clinic. Women and patients who worked as civil servants (OR 4.928) or farmers (OR 3.746), were workers (OR 3.439) or freelancers (OR 3.398), had no personal preference (OR 2.530), and were not concerned about close proximity (OR 2.030) were more likely to choose a specialised hospital. Patients who were older than 60 years of age, earned $<2000 \mathrm{CNY}$ per month (OR 4.630 ), had no personal preference (OR 4.607), were concerned about close proximity and short waiting times, pursued low medical costs, and did not express a preference for first-class medical technology (OR 26.698) were more likely to choose a CHF. Patients who earned $<2000 \mathrm{CNY}$ (OR 3.106) or between 2000 and 4999 CNY (OR 2.985) per month; were educated 
Open Access

Table 3 Influential factors of preference and choice of healthcare providers in mild illness

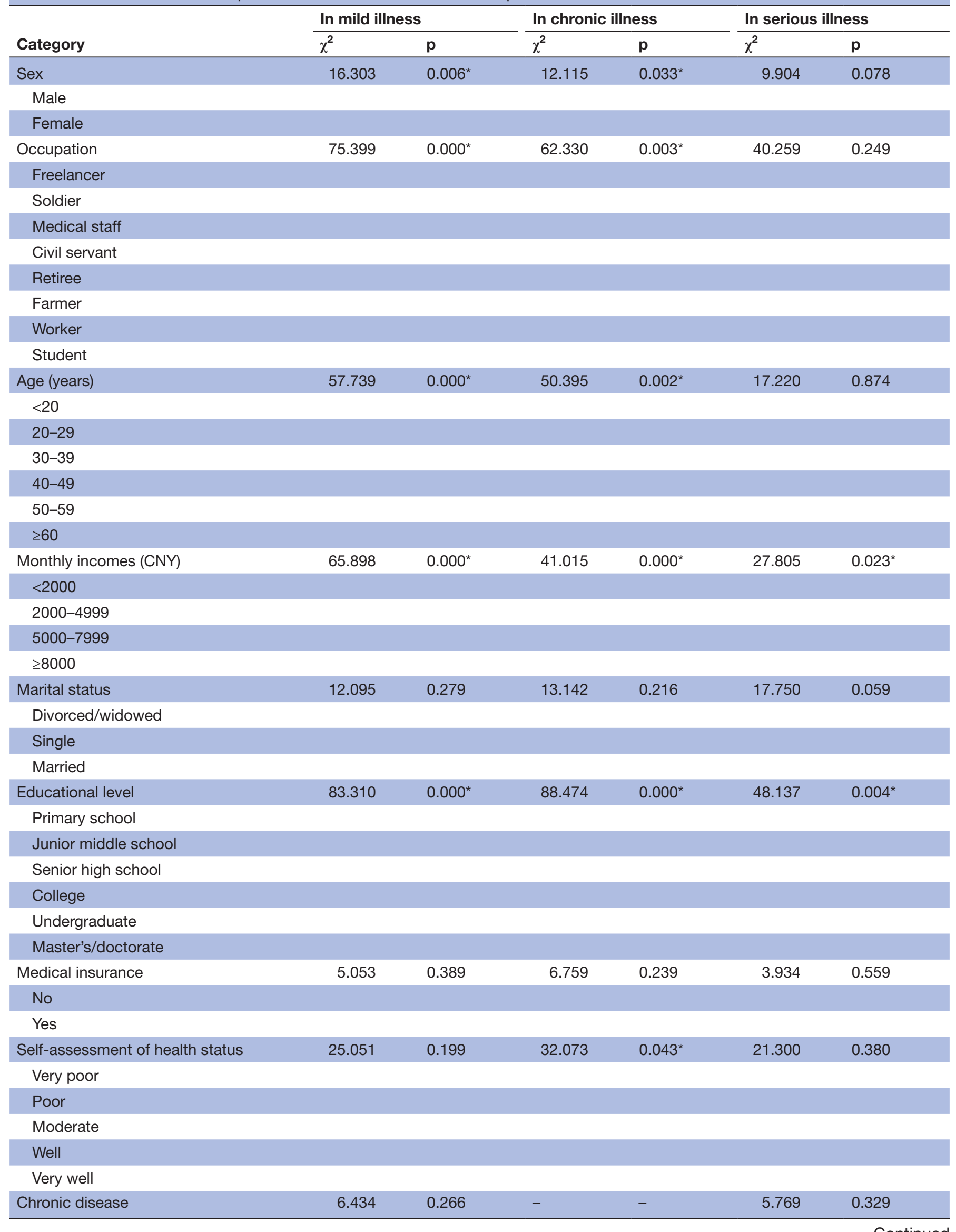


Table 3 Continued

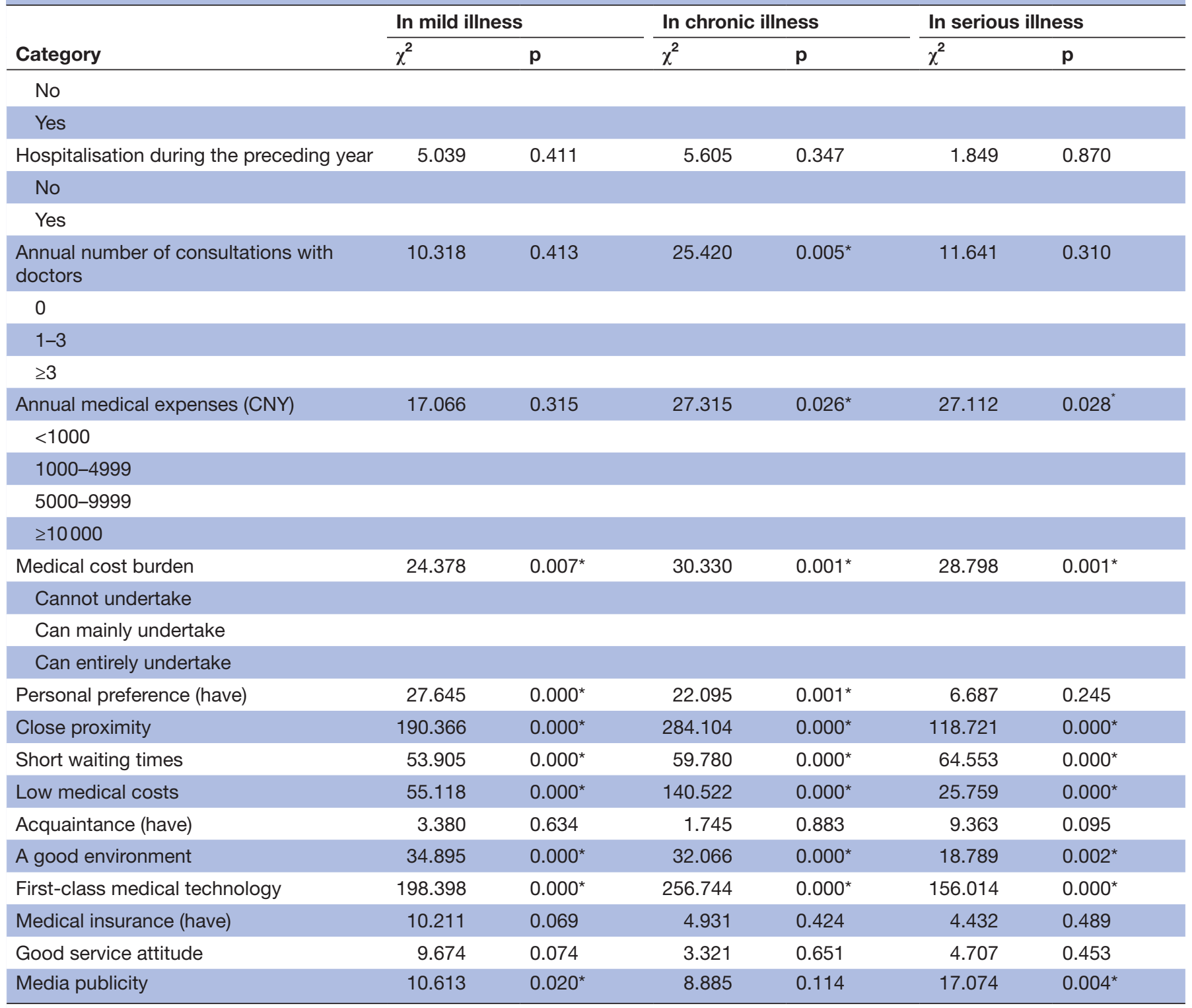

*Indicates statistically significant results $(p<0.05)$.

to primary school (OR 8.856), junior middle school (OR 7.334), senior high school (OR 7.399) or college (OR 4.346) level; reported few consultations with doctors (OR 2.521); had no personal preference (OR $3.570)$; were concerned about close proximity; and did not express a preference for first-class medical technology (OR 3.963) were more likely to choose a district hospital (table 5).

\section{Preference and choice of healthcare providers in serious illness}

Univariate analysis of influential factors

Factors included in the univariate analyses of factors for serious illness were similar to those included for mild illness. The results of the $\chi^{2}$ tests showed that the following factors exerted a significant effect on the choice of healthcare providers in serious illness: monthly income $(p=0.023)$, educational level $(p=0.004)$, annual medical expenses $(p=0.028)$, medical cost burden $(\mathrm{p}=0.001)$, close proximity $(p<0.0001)$, short waiting times $(p<0.0001)$, low medical costs $(p<0.0001)$, a good environment $(\mathrm{p}=0.002)$, first-class medical technology $(\mathrm{p}<0.0001)$, and media publicity $(\mathrm{p}=0.004$; table 3$)$.

Logistic regression analysis of the choice of healthcare providers in serious illness

The assignment of the dependent variable was similar to that in the logistic regression analysis of choice of healthcare providers in mild illness. The results indicated that factors affecting patients' choice of healthcare providers were significant only for specialised hospitals, CHFs, and district hospitals. Patients who were educated to junior middle school level (OR 3.439), were unable (OR 3.322) or only partially able to manage the burden of medical costs (OR 1.957), and were not concerned about the 
Open Access

Table 4 Logistic regression analysis of preference and choice of healthcare providers in mild illness*

\begin{tabular}{|c|c|c|c|c|c|}
\hline \multirow[b]{2}{*}{ Parameter } & \multirow[b]{2}{*}{ Estimate } & \multirow[b]{2}{*}{ p Value } & \multirow[b]{2}{*}{ OR } & \multicolumn{2}{|c|}{$95 \%$ Wald Cl } \\
\hline & & & & Lower limit & Upper limit \\
\hline \multicolumn{6}{|l|}{$Y=1$, drug stores } \\
\hline \multicolumn{6}{|l|}{ Occupation (ref: student) } \\
\hline Freelancer & 1.879 & 0.016 & 6.544 & 1.421 & 30.132 \\
\hline Farmer & 2.351 & 0.009 & 10.492 & 1.781 & 61.807 \\
\hline \multicolumn{6}{|l|}{ Age (ref: $\geq 60$ years) } \\
\hline$<20$ & 2.425 & 0.022 & 11.303 & 1.418 & 90.115 \\
\hline \multicolumn{6}{|c|}{ Educational level (ref: master's/doctorate) } \\
\hline Primary school & -2.564 & 0.015 & 0.077 & 0.010 & 0.608 \\
\hline Junior middle school & -1.597 & 0.040 & 0.202 & 0.044 & 0.931 \\
\hline Senior high school & -1.745 & 0.016 & 0.175 & 0.042 & 0.724 \\
\hline College & -2.248 & 0.003 & 0.106 & 0.024 & 0.463 \\
\hline Undergraduate & -1.258 & 0.048 & 0.284 & 0.082 & 0.990 \\
\hline \multicolumn{6}{|c|}{ Low medical costs (ref: yes) } \\
\hline No & -1.513 & 0.012 & 0.220 & 0.068 & 0.714 \\
\hline \multicolumn{6}{|c|}{ First-class medical technology (ref: yes) } \\
\hline No & 2.506 & 0.000 & 12.258 & 3.393 & 44.280 \\
\hline \multicolumn{6}{|l|}{$Y=2$, clinics } \\
\hline \multicolumn{6}{|l|}{ Age (ref: $\geq 60$ years) } \\
\hline$<20$ & 3.138 & 0.021 & 23.054 & 1.616 & 328.854 \\
\hline 30-39 & 2.168 & 0.044 & 8.742 & 1.063 & 71.905 \\
\hline \multicolumn{6}{|c|}{ Short waiting times (ref: yes) } \\
\hline No & -1.115 & 0.030 & 0.328 & 0.120 & 0.896 \\
\hline \multicolumn{6}{|c|}{ Low medical costs (ref: yes) } \\
\hline No & -1.615 & 0.005 & 0.199 & 0.064 & 0.621 \\
\hline \multicolumn{6}{|c|}{ First-class medical technology (ref: yes) } \\
\hline No & 1.684 & 0.004 & 5.390 & 1.735 & 16.743 \\
\hline \multicolumn{6}{|c|}{$Y=3$, specialised hospitals } \\
\hline \multicolumn{6}{|l|}{ Occupation (ref: student) } \\
\hline Soldier & 3.821 & 0.008 & 45.666 & 2.748 & 758.748 \\
\hline Civil servant & 2.981 & 0.017 & 19.705 & 1.688 & 230.016 \\
\hline \multicolumn{6}{|c|}{ Personal preference (ref: yes) } \\
\hline No & 0.974 & 0.038 & 2.648 & 1.053 & 0.655 \\
\hline \multicolumn{6}{|c|}{ Close proximity (ref: yes) } \\
\hline No & 1.039 & 0.016 & 2.827 & 1.210 & 0.607 \\
\hline \multicolumn{6}{|c|}{$Y=4$, community health facilities } \\
\hline \multicolumn{6}{|l|}{ Sex (ref: female) } \\
\hline Male & 0.643 & 0.001 & 1.902 & 1.297 & 2.788 \\
\hline \multicolumn{6}{|c|}{ Personal preference (ref: yes) } \\
\hline No & 0.789 & 0.002 & 2.200 & 1.331 & 3.637 \\
\hline Close proximity (ref: yes & & & & & \\
\hline No & -1.324 & 0.000 & 0.266 & 0.175 & 0.404 \\
\hline Short waiting times (ref: & & & & & \\
\hline No & -1.112 & 0.000 & 0.329 & 0.185 & 0.584 \\
\hline Low medical costs (ref: & & & & & \\
\hline
\end{tabular}


Table 4 Continued

\begin{tabular}{|c|c|c|c|c|c|}
\hline \multirow[b]{2}{*}{ Parameter } & \multirow[b]{2}{*}{ Estimate } & \multirow[b]{2}{*}{ p Value } & \multirow[b]{2}{*}{ OR } & \multicolumn{2}{|l|}{ 95\% Wald Cl } \\
\hline & & & & Lower limit & Upper limit \\
\hline No & -1.376 & 0.001 & 0.253 & 0.111 & 0.575 \\
\hline \multicolumn{6}{|c|}{ A good environment (ref: yes) } \\
\hline No & 0.727 & 0.036 & 2.068 & 1.049 & 4.077 \\
\hline \multicolumn{6}{|c|}{ First-class medical technology (ref: yes) } \\
\hline No & 2.118 & 0.000 & 8.311 & 4.655 & 14.837 \\
\hline \multicolumn{6}{|l|}{$Y=5$, district hospitals } \\
\hline \multicolumn{6}{|c|}{ Educational level (ref: master's/doctorate) } \\
\hline Junior middle school & 1.486 & 0.014 & 4.421 & 1.345 & 14.535 \\
\hline Senior high school & 1.382 & 0.018 & 3.982 & 1.271 & 12.477 \\
\hline College & 1.122 & 0.049 & 3.071 & 1.003 & 9.404 \\
\hline \multicolumn{6}{|c|}{ Personal preference (ref: yes) } \\
\hline No & 0.680 & 0.011 & 1.973 & 1.165 & 3.341 \\
\hline \multicolumn{6}{|l|}{ Close proximity (ref: yes) } \\
\hline No & -1.333 & 0.000 & 0.264 & 0.171 & 0.407 \\
\hline \multicolumn{6}{|c|}{ Short waiting times (ref: yes) } \\
\hline No & -0.745 & 0.019 & 0.475 & 0.254 & 0.887 \\
\hline \multicolumn{6}{|c|}{ First-class medical technology (ref: yes) } \\
\hline No & 0.939 & 0.000 & 2.557 & 1.556 & 4.201 \\
\hline
\end{tabular}

*The multinomial logistic regression analysis required to choose one classification of the dependent factor as the referred category, which was used to fit the logistic regression models of the other classifications of the dependent factor relative to this referred category. In this analysis, the referred category was defined as choosing general hospitals.

environment of the healthcare institution (OR 1.986) were more likely to choose a specialised hospital. Patients who were concerned about short waiting times and did not express a preference for first-class medical technology (OR 21.333) were more likely to choose a CHF. Patients who reported monthly incomes $<1000 \mathrm{CNY}$ (OR 5.063), between 1000 and 4999 CNY (OR 3.602), or between 5000 and $9999 \mathrm{CNY}$ (OR 5.583) per month; were unable (OR 8.181) or only partially able (OR 4.647) to manage the burden of medical costs; were concerned about close proximity; and did not express a preference for firstclass medical technology (OR 7.676) were more likely to choose a district, rather than a general, hospital (table 6).

\section{DISCUSSION}

The survey results indicated that participants' sociodemographic characteristics constituted the main factor influencing patients' preference and decision to seek medical treatment, followed by healthcare providers' characteristics and participants' illness severity.

Currently, more than half of the Chinese population is unlikely to seek medical treatment when ill, for various reasons. However, the likelihood that adolescents (ie, younger than 20 years of age) would not seek treatment was lower relative to that observed for elderly people (ie, older than 60 years of age). This finding could have occurred because parents and families can more easily recognise ailments of their children. This is consistent with the results of a study involving teenagers with insomnia in Hong Kong, ${ }^{31}$ in which parents were more likely to recognise morning headaches as a symptom of insomnia in their children and seek medical help. In addition, self-treatment has been shown to play a significant role in other populations who fail to seek medical treatment. McCombie defined self-treatment as "not refer(ring) to any healthcare consultant or traditional healer, and their diagnosis and treatment," ${ }^{32}$ and it is a particularly common phenomenon in developing countries such as China. Moreover, because of the spread of traditional Chinese medicine and easy access to over-the-counter medication, most Chinese people prefer self-treatment if their symptoms are not serious or complementary medicine is available. In addition, self-treatment has numerous advantages; for example, it saves time, as it eliminates the need to consult a doctor, and reduces medical costs, as individuals are required to pay only for medication, rather than diagnosis, treatment, and other healthcare services. Therefore, self-treatment is a suitable alternative for individuals with heavy workloads and economic burden.

The results of the current data analysis and existing studies suggest that people who pursued low medical costs, were not concerned about short waiting times, and did not express a preference for first-class medical technology ${ }^{33}$ were likely to choose other 
Open Access

Table 5 Logistic regression analysis of preference and choice of healthcare providers in chronic diseases*

95\% Wald CI

\begin{tabular}{|c|c|c|c|c|c|}
\hline Parameter & Estimate & p Value & OR & Lower limit & Upper limit \\
\hline \multicolumn{6}{|c|}{$Y=1$, drug stores } \\
\hline \multicolumn{6}{|c|}{ Sex (ref: female) } \\
\hline Male & 2.532 & 0.023 & 12.585 & 1.428 & 110.919 \\
\hline \multicolumn{6}{|c|}{ Annual medical expenses (ref: $\geq 10000 \mathrm{CNY}$ ) } \\
\hline $1000-4999$ & -3.254 & 0.042 & 0.039 & 0.002 & 0.892 \\
\hline \multicolumn{6}{|c|}{ Short waiting times (ref: yes) } \\
\hline No & -2.639 & 0.015 & 0.071 & 0.009 & 0.595 \\
\hline \multicolumn{6}{|c|}{ Low medical costs (ref: yes) } \\
\hline No & -4.146 & 0.001 & 0.016 & 0.002 & 0.165 \\
\hline \multicolumn{6}{|c|}{ First-class medical technology (ref: yes) } \\
\hline No & 1.965 & 0.026 & 7.135 & 1.266 & 40.203 \\
\hline \multicolumn{6}{|l|}{$Y=2$, clinics } \\
\hline \multicolumn{6}{|c|}{ Low medical costs (ref: yes) } \\
\hline No & -4.806 & 0.000 & 0.008 & 0.001 & 0.091 \\
\hline \multicolumn{6}{|c|}{$Y=3$, specialised hospitals } \\
\hline \multicolumn{6}{|l|}{ Sex (ref: female) } \\
\hline Male & -0.470 & 0.024 & 0.625 & 0.416 & 0.939 \\
\hline \multicolumn{6}{|c|}{ Occupation (ref: student) } \\
\hline Freelancer & 1.223 & 0.031 & 3.398 & 1.116 & 10.349 \\
\hline Civil servant & 1.595 & 0.027 & 4.928 & 1.202 & 20.206 \\
\hline Farmer & 1.321 & 0.035 & 3.746 & 1.097 & 12.786 \\
\hline Worker & 1.235 & 0.038 & 3.439 & 1.070 & 11.054 \\
\hline \multicolumn{6}{|c|}{ Personal preference (ref: yes) } \\
\hline No & 0.928 & 0.008 & 2.530 & 1.275 & 5.019 \\
\hline \multicolumn{6}{|c|}{ Close proximity (ref: yes) } \\
\hline No & 0.708 & 0.040 & 2.030 & 1.033 & 3.988 \\
\hline
\end{tabular}

$Y=4$, community health facilities

Age (ref: $\geq 60$ years)

\begin{tabular}{|c|c|c|c|c|c|}
\hline $50-59$ & -1.072 & 0.019 & 0.342 & 0.140 & 0.836 \\
\hline \multicolumn{6}{|c|}{ Monthly incomes (ref: $\geq 8000$ CNY) } \\
\hline$<2000$ & 1.533 & 0.038 & 4.630 & 1.089 & 19.695 \\
\hline \multicolumn{6}{|c|}{ Personal preference (ref: yes) } \\
\hline No & 1.528 & 0.000 & 4.607 & 2.049 & 10.358 \\
\hline \multicolumn{6}{|c|}{ Close proximity (ref: yes) } \\
\hline No & -1.943 & 0.000 & 0.143 & 0.080 & 0.255 \\
\hline \multicolumn{6}{|c|}{ Short waiting times (ref: yes) } \\
\hline No & -1.229 & 0.002 & 0.293 & 0.137 & 0.626 \\
\hline \multicolumn{6}{|c|}{ Low medical costs (ref: yes) } \\
\hline No & -2.581 & 0.000 & 0.076 & 0.024 & 0.241 \\
\hline \multicolumn{6}{|c|}{ First-class medical technology (ref: yes) } \\
\hline No & 3.391 & 0.000 & 29.698 & 11.493 & 76.745 \\
\hline \multicolumn{6}{|c|}{$Y=5$, district hospitals } \\
\hline \multicolumn{6}{|c|}{ Monthly incomes (ref: $\geq 8000 \mathrm{CNY}$ ) } \\
\hline$<2000$ & 1.133 & 0.045 & 3.106 & 1.024 & 9.418 \\
\hline
\end{tabular}




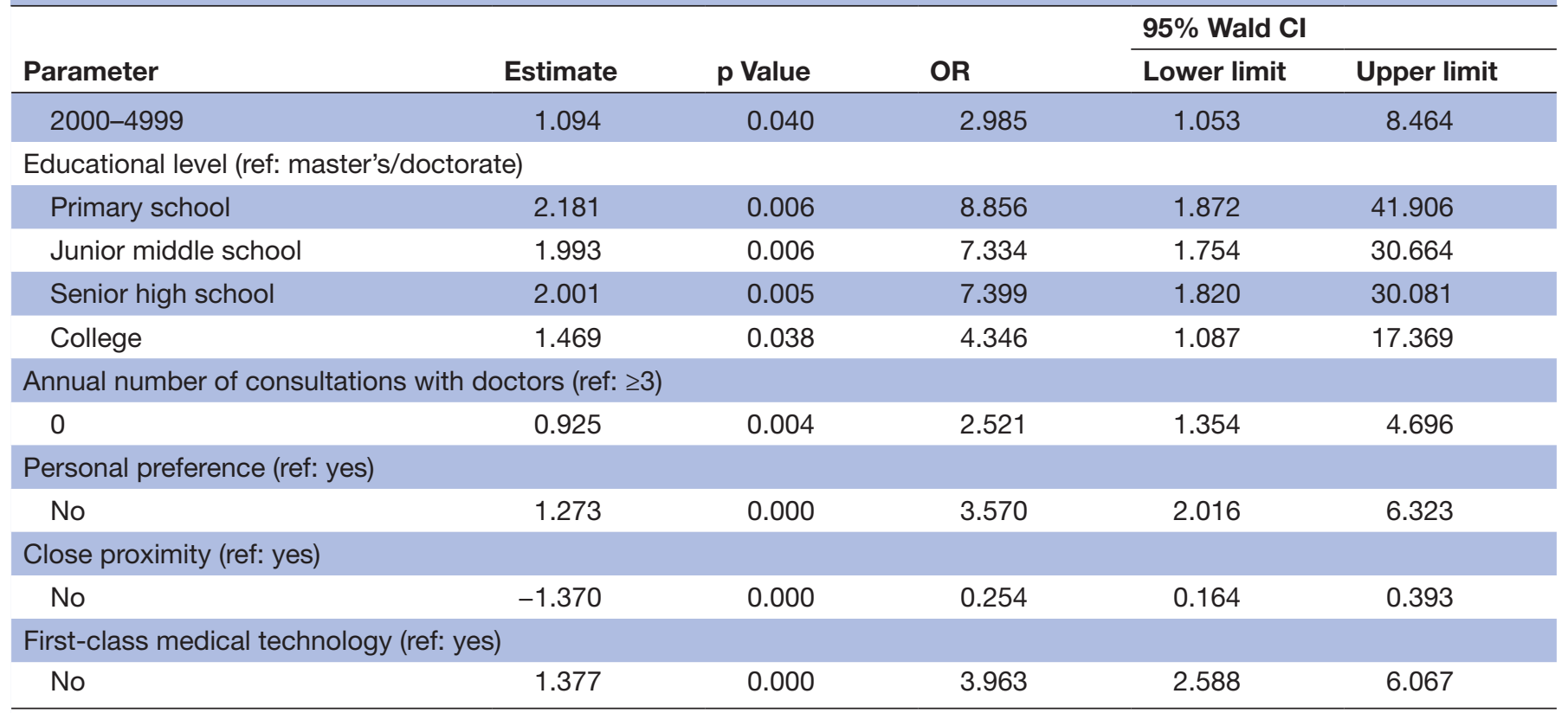

*The multinomial logistic regression analysis required to choose one classification of the dependent factor as the referred category, which was used to fit the logistic regression models of the other classifications of the dependent factor relative to this referred category. In this analysis, the referred category was defined as choosing general hospitals.

healthcare providers rather than general hospitals. Indeed, general hospitals in China are characterised by high-level medical technology, high medical costs, and long waiting times; however, they remain the most popular choice for patients. ${ }^{3} 34$ We incorporated this well-known phenomenon into the aim of the study and endeavoured to identify means of transforming this unreasonable healthcare-seeking preference by determining the key influential factors and ascertaining the shortcomings of other types of healthcare provider. The findings indicated that drug stores and clinics are suitable alternatives to general hospitals for people who pursue low medical costs and convenience. ${ }^{35}$ People also choose to visit drug stores because they do not need to pay for diagnosis, treatment, or laboratory tests. However, many decide against this course of action because drug stores do not provide diagnoses or comprehensive treatment. In addition, individuals could save money by choosing to visit clinics, because the costs of medical care are determined by clinic owners, who usually offer treatment at considerably lower prices, relative to those of general hospitals, to attract patients. However, the standards in Chinese clinics fall far below those of clinics in developed countries. For instance, most clinics provide low-level care, many of their doctors' do not hold recognised qualifications, and the healthcare business avoids monitoring by the supervision department. ${ }^{16}$ These issues could explain why only a small proportion of participants chose to visit clinics. Moreover, in addition to general hospitals, specialised hospitals, district hospitals, and CHFs are popular healthcare providers. In China, specialised hospitals are especially good for some diseases (eg, cancer, gynaecology and obstetrics, and stomatology ${ }^{36}$; however, the number of specialised hospitals (4665) is considerably lower relative to that of general hospitals $\left(\begin{array}{ll}15 & 021\end{array}\right) .^{5}$ Therefore, specialised hospitals are distributed much more sparsely relative to general hospitals, and attendance is often inconvenient because of transportation issues. Moreover, previous studies showed that the proximity of health institutions to patients homes exerted a significant effect on patients' healthcare-seeking preferences, and the decisions of elderly individuals in particular were influenced by this factor. ${ }^{37}$ Consequently, specialised hospitals could have been less popular, relative to general hospitals, because patients were required to travel longer distances to reach them, and transportation was inconvenient. In contrast, CHFs are located in communities and easily accessible to all community residents. Similarly, district hospitals serve several communities, within which the necessary transportation is convenient. Therefore, CHFs and district hospitals could share a large proportion of the patient population, as close proximity to patients' homes is a strong advantage.

Illness severity has been identified as another important factor influencing patients' healthcare-seeking preferences $^{11}$; and patients with severe illness have been shown to prefer hospitals with superior care and treatment options, ${ }^{30}$ which is consistent with the findings of the current study. Specifically, most patients with mild illness tended to select CHFs or district hospitals; this finding 
Table 6 Logistic regression analysis of preference and choice of healthcare providers in serious diseases ${ }^{*}$

\begin{tabular}{|c|c|c|c|c|c|}
\hline \multirow[b]{2}{*}{ Parameter } & \multirow[b]{2}{*}{ Estimate } & \multirow[b]{2}{*}{ p Value } & \multirow[b]{2}{*}{ OR } & \multicolumn{2}{|l|}{ 95\% Wald Cl } \\
\hline & & & & Lower limit & Upper limit \\
\hline \multicolumn{6}{|c|}{$Y=3$, specialised hospitals } \\
\hline \multicolumn{6}{|c|}{ Educational level (ref: master's/doctorate) } \\
\hline Junior middle school & 1.235 & 0.018 & 3.439 & 1.231 & 9.612 \\
\hline \multicolumn{6}{|c|}{ Medical cost burden (ref: can entirely undertake) } \\
\hline Cannot undertake & 1.201 & 0.001 & 3.322 & 1.612 & 6.847 \\
\hline Can mainly undertake & 0.671 & 0.044 & 1.957 & 1.017 & 3.763 \\
\hline \multicolumn{6}{|c|}{ A good environment (ref: yes) } \\
\hline No & 0.686 & 0.009 & 1.986 & 1.185 & 3.327 \\
\hline \multicolumn{6}{|c|}{$Y=4$, community health facilities } \\
\hline \multicolumn{6}{|c|}{ Short waiting times (ref: yes) } \\
\hline No & -1.714 & 0.002 & 0.180 & 0.061 & 0.535 \\
\hline \multicolumn{6}{|c|}{ First-class medical technology (ref: yes) } \\
\hline No & 3.060 & 0.000 & 21.333 & 6.105 & 74.548 \\
\hline \multicolumn{6}{|l|}{$Y=5$, district hospitals } \\
\hline \multicolumn{6}{|c|}{ Annual medical expenses (ref: $\geq 10000 \mathrm{CNY}$ ) } \\
\hline$<1000$ & 1.622 & 0.012 & 5.063 & 1.428 & 17.957 \\
\hline $1,000-4999$ & 1.282 & 0.038 & 3.602 & 1.075 & 12.073 \\
\hline $5,000-9999$ & 1.720 & 0.012 & 5.583 & 1.453 & 21.451 \\
\hline \multicolumn{6}{|c|}{ Medical cost burden (ref: can entirely undertake) } \\
\hline Cannot undertake & 2.102 & 0.008 & 8.181 & 1.716 & 39.015 \\
\hline Can mainly undertake & 1.536 & 0.043 & 4.647 & 1.048 & 20.602 \\
\hline \multicolumn{6}{|l|}{ Close proximity (ref: yes) } \\
\hline No & -1.253 & 0.000 & 0.286 & 0.161 & 0.507 \\
\hline \multicolumn{6}{|c|}{ First-class medical technology (ref: yes) } \\
\hline No & 2.038 & 0.000 & 7.676 & 4.048 & 14.557 \\
\hline
\end{tabular}

*The multinomial logistic regression analysis required to choose one classification of the dependent factor as the referred category, which was used to fit the logistic regression models of the other classifications of the dependent factor relative to this referred category. In this analysis, the referred category was defined as choosing general hospitals.

could have occurred because the patients were likely to have experienced relatively minor symptoms and did not require first-class medical technology. Therefore, CHFs and district hospitals, in which medical technology is sufficient for the treatment of common illnesses or injuries but does not meet the needs of those with serious illnesses, were suitable alternatives to general hospitals. ${ }^{38}$ Fortunately, the community-first treatment and two-way referral systems in Shanghai reflect this pattern of preference to some extent (although acceptance is not universal). ${ }^{39}$ Another survey conducted in $20 \mathrm{CHFs}$ in Kunming city in China demonstrated similar findings, in that $65 \%$ of patients chose CHFs for treatment of non-critical illnesses. ${ }^{40}$ Moreover, considering the longterm nature of their illness, their future health, and their healthcare utilitisation, ${ }^{41}$ patients with chronic illness are likely to prioritise prevention, treatment, management, and first-class medical technology over close proximity. ${ }^{42}$ Furthermore, general, specialised, and district hospitals are likely to be chosen by patients with different opinions and economic circumstances, because of the long-term burden of medical costs ${ }^{16}$ and their capacity to treat and manage chronic illness. ${ }^{18}$ In addition, serious illness is critical, difficult, and urgent in nature and requires treatment using first-class medical technology. Consequently, general hospitals, which possess the strongest overall treatment capacity, and specialised hospitals, which provide superior treatment for specific serious illnesses, are the most suitable choices for patients with serious illness. ${ }^{43}$

Participants' sociodemographic characteristics, particularly age group, income, and educational level, were also identified as important factors influencing patients' healthcare-seeking preference. One possible explanation for the finding that young people were most likely to choose drug stores and clinics is that they had greater access to medical information via various media (eg, the internet) and were able to purchase medication for self-treatment. Furthermore, they are more likely 
to accept new concepts in recent policy supporting the development of private health institutions such as clinics. In contrast, elderly people were more likely to choose CHFs because of their close proximity and convenient transportation. ${ }^{3}{ }^{42}$ In addition, people on low incomes have been shown to be inclined to choose CHFs and district hospitals, as the medical costs are relatively low. ${ }^{41}$ Moreover, owing to the lack of GPs' suggestions for an appropriate hospital or specialists in the Chinese healthcare system, ${ }^{42}$ people with low educational levels have to choose medium-level healthcare providers (ie, district hospitals). In addition, most people with low educational levels are on low incomes, ${ }^{44}$ which could provide a partial explanation for the finding that they were more likely to choose district hospitals with low medical costs.

\section{Limitations}

The study was subject to four limitations. First, the results showed that medical insurance coverage did not affect patients' healthcare-seeking preference, which is inconsistent with the findings of most previous studies. ${ }^{10} 16$ However, some research in the literature pointed out that findings indicating a weak effect of medical insurance could occur because of the presence of confounding factors. ${ }^{45}$ In addition, medical insurance was not categorised into different types in the study, which could have been one of the reasons for this result. Therefore, further research is required to determine whether this finding could be explained by the fact that almost all of the study participants had medical insurance. Second, many previous studies considered social, cultural, and psychological factors, ${ }^{13}{ }^{19}$ which were excluded from the current study and will be examined in follow-up research. Third, because most people in China choose tertiary hospitals when seeking medical treatment, these patients in tertiary hospitals can partly represent the whole group of patients, and it can be easier to understand why they choose tertiary hospitals and when they will choose other healthcare providers. In addition, some existing studies were also performed in hospitals, ${ }^{3} 34$ which proved the reasonability of this study to some extent. Therefore, it can be understood why we conducted this survey only in tertiary hospitals. However, we acknowledge that patients in tertiary hospitals do not represent the overall healthcare situation in China. Future studies should increase the representativeness of this research. Fourth, the questionnaire used to collect data regarding sociodemographic characteristics did not include an item pertaining to whether participants were local residents of Shanghai, which was important information and could have enhanced the interpretation of the findings; however, this will be included in the questionnaire in the follow-up study.

\section{CONCLUSION}

The results of the study indicate that the proportion of people in China who do not seek medical treatment when they are ill is high, and most people in Shanghai, particularly those with chronic or serious illnesses, would prefer to be treated in general hospitals. However, CHFs were underutilised, as only a third of patients had chosen these facilities when they had experienced mild illness, which is vastly inconsistent with the WHO's suggestion that between $70-80 \%$ of common illnesses could be treated in CHFs. ${ }^{46}{ }^{47}$ The main factors influencing healthcare-seeking preference included the health institutions' characteristics, illness severity, and participants' sociodemographic characteristics. In addition, the CHFs' capability for providing healthcare services should be improved to optimise patients' healthcare-seeking preference. Moreover, CHFs should accept greater responsibility for the prevention and management of mild and chronic illness, which would reduce not only medical costs but also the burden faced by general and specialised hospitals.

Contributors Three authors, WY, ML, and FY, contributed equally to this research. WY, ML, FY, CX, and LZ prepared the manuscript. WY made substantial contributions to the study conception and design, analysis and interpretation of data, drafting the manuscript, and revising the manuscript critically for important intellectual content. ML and FY made substantial contributions to the study conception and design, interpretation of data, and drafting the manuscript. CX contributed to the data collection and manuscript revision. LZ made substantial contributions to the study conception and design. All of the authors approved the final version of the manuscript and agreed with submission for publication.

Funding The project was supported by National Natural Science Foundation of China (71233008, 71303248, 71673291), Important Disease Joint Research Project in Health Systems of Shanghai (2013ZYJB0006), and Military Health Support Strategy and Key Technology Research for Special Injuries in the South China Sea Region (AWS12J002).

Competing interests None declared.

Patient consent Obtained.

Ethics approval Ethics Committee of Second Military Medical University.

Provenance and peer review Not commissioned; externally peer reviewed.

Data sharing statement No additional data are available.

Open Access This is an Open Access article distributed in accordance with the Creative Commons Attribution Non Commercial (CC BY-NC 4.0) license, which permits others to distribute, remix, adapt, build upon this work non-commercially, and license their derivative works on different terms, provided the original work is properly cited and the use is non-commercial. See: http://creativecommons.org/ licenses/by-nc/4.0/

(c) Article author(s) (or their employer(s) unless otherwise stated in the text of the article) 2017. All rights reserved. No commercial use is permitted unless otherwise expressly granted.

\section{REFERENCES}

1. Chen B, Li XB, Lu YJ, et al. Agent-based modeling and simulation research into residents healthcare choice. System Eng 2009;27:96-101.

2. Guo YT. Residents' choice of medical services and its difference between urban and rural resident. Med Philos 2014;35:40-2.

3. Wei M, Xiao JC. Study on influencing factors and countermeasures analyses of choosing different medical institutions by patients. Chin Health Serv Manage 2014;31:259-61.

4. Centre for Health Statistics and Information, MOH China. Analysis report of National Health Services Survey in China. 2008.

5. Pecking Union Medical College Press. Statistic yearbook of national health and family planning of the People's Republic of China 2013. Beijing: Pecking Union Medical College Press, 2014.

6. Li HB, Yuan MX. Promoting continuing education of grassroots doctors by using health resources in tertiray hospitals effectively. Chinese Clinical Doctor 2016;11:99-101. 
7. Yang JH, He P, Gao XC, et al. Discussion on optimizing the process of one-stop self-service in municipal hospitals of Shanghai. Chin J Hosp Admin 2015;31:598-601.

8. Wu XY, Zhu YN, Sun HW, et al. Survey on doctors' cognition and intention about work burden, work satisfaction and manpower distribution. Chin Health Serv Manage 2007;23:23-4.

9. Dou WJ, Zhao F, Gu JL, et al. Survey of rural residents' wills to medical treatment and its influencing factors in Shandong province. Chin J Gen Pract 2015;13:1484-5.

10. Wang HP, Liu XY, Sun XJ, et al. Effect of Chinese health care reform on medical behavior of diabetics in rural areas. Chin $J$ Public Health 2013;6:042.

11. Wang $M$, Zhang KJ, Jiang L, et al. Impact factors model of medical behavior of Chinese urban and rural residents. Chin J Gen Pract 2010;13:2127-9.

12. Lv LH, Ji YD, Zhang YX, et al. Demand for and intention to medical care among infertile men. Chin J Reprod Health 2013;24:34-6.

13. Kuan YC, Yen DJ, Yiu CH, et al. Treatment-seeking behavior of people with epilepsy in Taiwan: a preliminary study. Epilepsy Behav 2011;22:308-12.

14. Fang PQ, Guo SL, Tao HB, et al. Study on employees' willingness of medical treatment in the development zone of Wuhan. Chin J Soc Med 2008;25:119-21.

15. Zhang Y, Ji Y, Zhang F, et al. Intentions for seeking medical care among the peasant workers in the construction industry of Beijing and relevant influential factors. Occup Health 2008;24:1-4.

16. Bing SS, Yin AT, Meng QY, et al. Study on the rural chronic patients' medical treatment choice. Chin Health Econ 2010;29:32-4.

17. Lv LH, Liu SH, Zhang YX, et al. Demand for and intention to medical care among infertile women. Chin J Reprod Health 2013;28:265-7.

18. Zhang SR, Liu XL, Zhao ZG, et al. Health seeking behavior and its influencing factors of the senior citizens in Shenzhen. Chin J Geriatr 2010;29:336-8.

19. Wu CY, Liu SI, Chang SS, et al. Surveys of medical seeking preference, mental health literacy, and attitudes toward mental illness in Taiwan, 1990-2000. J Formos Med Assoc 2014;113:33-41.

20. Chen $Y$, Huang YS. Medical choice of women with gynopathy in Guangxi. Ethno-Natl Stud 2014;6:007.

21. Johnson P, Bancroft T, Barron R, et al. Discrete choice experiment to estimate breast cancer patients' preferences and willingness to pay for prophylactic granulocyte colony-stimulating factors. Value Health 2014;17:380-9.

22. Praptiningsih CY, Lafond KE, Wahyuningrum Y, et al. Healthcareseeking behaviors for acute respiratory illness in two communities of Java, Indonesia: a cross-sectional survey. J Epidemiol Glob Health 2016;6:77-86.

23. Altice NF, Madigan EA. Factors associated with delayed careseeking in hospitalized patients with heart failure. Heart Lung 2012;41:244-54.

24. Ringard $\AA$, Saunes IS, Sagan A. The 2015 hospital treatment choice reform in Norway: continuity or change? Health Policy 2016;120:350-5.

25. Zimmermann TM, Clouth J, Elosge M, et al. Patient preferences for outcomes of depression treatment in Germany: a choice-based conjoint analysis study. J Affect Disord 2013;148:210-9.

26. Hvidberg L, Wulff CN, Pedersen AF, et al. Barriers to healthcare seeking, beliefs about cancer and the role of socio-economic position. A Danish population-based study. Prev Med 2015;71:107-13.
27. O’Mahony M, Hegarty J, McCarthy G. Women's help seeking behaviour for self discovered breast cancer symptoms. Eur J Oncol Nurs 2011;15:410-8.

28. Jayapalan S. Determinants of delay in the health care seeking behaviour of STD patients. Clin Epidemiol Glob Health 2015;3:S69-S74.

29. Li F, Jin CL, Wang LN, et al. Analysis of the status and impact of patients from the allopatry in Shanghai. Chinese Health Economics 2012;31:42-5.

30. Chen R, Du XD, Yang Z, et al. Analysis of choice of healthcare services and the influencing factors among outpatients in Chengdu city. Modern Preventive Medicine 2016;43:4217-20.

31. Liu Y, Zhang J, Lam SP, et al. Help-seeking behaviors for insomnia in Hong Kong Chinese: a community-based study. Sleep Med 2016;21:106-13.

32. McCombie SC. Self-treatment for malaria: the evidence and methodological issues. Health Policy Plan 2002;17:333-44.

33. Peng $W$, Wang $X Y$, Peng $Y C$, et al. Field observation research on the medical choice of residents in a certain district of Beijing. Chin $J$ of Hos Adm 2010;26:688-90.

34. Zen D, Li ZX, Duan ZQ, et al. Hospitalization options of patients in urban areas, Sichuan province. Mod Prev Med 2015;42:1631-5.

35. Wang $\mathrm{N}$, Chen $\mathrm{Q}, \mathrm{Wu} \mathrm{JJ}$, et al. A simple correspondence analysis on the willingness of choosing medical institutions of residents in Shenzhen. Contemp Med 2015;21:3-5.

36. Sun RG. Development and countermeasure to specialized hospitals in our country. Soft Sci Health 2012;26:94-6.

37. Wu H, Ge Cy, Jia HY, et al. Survey on utilization intent of community health services in Beijing Fangzhuang community. Chin J Gen Pract 2011;10:491-2.

38. Zhou Q, Liu GE. Studying on the influence of regional medical cooperation on residents' selection of healthcare sampled with Wenchuan county. Chin Health Serv Manage 2015;32:404-7.

39. Bao $Y, D u X L$, Liang $Y$. Analysis of the current situation and influencing factors of the first community treatment service in Shanghai based on the general practitioner system. Chin J Gen Pract 2012;10:333-4.

40. Zhao $Y$, Shen $X Y$, Huang $Q$, et al. Willingness of seeking medical services and relevant determinants among community residents. $J$ Prev Med Inform 2014;30:418-18.

41. Xie L, Zhang Y, Zheng XH. An analysis of medical choice of residents in Chengdu and Bazhong with the method of utility function. Chin Health Serv Manage 2007;23:129-30.

42. Berendsen AJ, de Jong GM, Schuling J, et al. Patient's need for choice and information across the interface between primary and secondary care: a survey. Patient Educ Couns 2010;79:100-5.

43. Ma Zq, Zhu Y, Zhu YY, et al. Research on choice of seeking medical care by residents based on customer delivered value. Chin Gen Prac 2013;16:787-9.

44. Hu HY. Analysis of the influence of education on personal income. Guide Bus 2010;6:248-9.

45. Robyn PJ, Fink G, Sié A, et al. Health insurance and health-seeking behavior: evidence from a randomized community-based insurance rollout in rural Burkina Faso. Soc Sci Med 2012;75:595-603.

46. Wan BH, Liu S, Fen XL, et al. Analysis of existing problems and solutions of the implementation of two-way referral in Changchun. Med Soc 2007;20:31-3.

47. Yu W, Li M, Nong X, et al. Practices and attitudes of doctors and patients to downward referral in Shanghai, China. BMJ Open 2017;7:e012565. 